Endocrinol. Japon. 1966, 13 (1), 39 45

\title{
STUDIES ON THE BIOSYNTHESIS OF STEROL AND GORTICOSTERONE IN RAT ADRENAL GLAND
}

\author{
Shogo ICHII ANd Shigeru KOBAYASHI \\ Division of Physiology and Pathology, National Institute of \\ Radiological Sciences, Chiba-shi, Japan
}

An obligatory role for cholesterol in the biosynthesis of steroid hormones seems to be generally accepted. Werbin and Chaikoff (1961) fed cholesterol-4-14 $\mathrm{C}$ to guinea pigs for 5 weeks and compared the specific activity of plasma cholesterol, adrenal cholesterol and cortisol isolated from urine. Although the specific activity of the adrenal cholesterol was only $60 \%$ of that of plasma cholesterol, the urinary cortisol had the same specific activity as the adrenal cholesterol. Similar findings were also reported by Krum et al. (1964) using dogs as the experimental animals. These authors interpreted these findings as evidence that cholesterol is an obligatory precursor of cortisol in these animals. The role of acetate as a substrate for steroid biosynthesis is now well established (Brady, 1951; Haynes et al., 1954; Hechter et al., 1953; Zaffaroni et al., 1951). However, measurements of the specific activity of cholesterol $-{ }^{14} \mathrm{C}$ formed from acetate- ${ }^{14} \mathrm{C}$ during the biosynthesis of ${ }^{14} \mathrm{C}$ labelled C-21-steroids by endocrine tissues in vitro have revealed that the specific activities of the labelled steroids are higher than that of the cholesterol- ${ }^{14} \mathrm{C}$ isolated from the same tissue (Bligh et al., 1955; Hall, 1963 ; Hechter et al., 1953). Such findings have led to two suggestions; one was that much of the cholesterol in steroid forming tissue is not available for steroid biosynthesis (Armstrong et al., 1964) and the other was the existence of an alternative pathway which did not involve cholesterol (Hall, 1963). In a previous report from this laboratory (Ichii et al., 1965), evidence was obtained that a small fraction of the cholesterol is being utilized for steroid hormone synthesis by rat adrenal.

The present series of experiments were undertaken to obtain more information about the steroid hormone precursor sterol in the biosynthesis of corticosteroids of rat adrenal gland.

\section{MATERIALS AND METHODS}

Sodium acetate- $1-{ }^{14} \mathrm{C}$ (Sp. Act. $53 \mathrm{mC} / \mathrm{m}$ mole) was obtained from New England Nuclear Corp. Nicotinamide adenine dinucleotide phosphate reduced (NADPH) and 3', 5' -cyclic adenosine monophosphate (cyclic AMP) were obtained from Sigma Chemical Co. Adrenocorticotrophic hormone (ACTH) used in this experiments was Acthar (Armour Co.).

Adrenals were obtained from Wistar rats weighing 200 to $250 \mathrm{~g}$. Animals were sacrificed by exanguination, adrenals were removed, freed from surrounding fat and quartered with a thin razor blade. Four hundred $\mathrm{mg}$ of quartered adrenal obtained from 10 rats were used for each

Received for publication September 29, 1965 
incubation. Tissues were incubated for $2 \mathrm{hrs}$. at $37^{\circ} \mathrm{C}$ in $4 \mathrm{ml}$ Krebs-Ringer-bicarbonate buffer solution containing $20 \mu \mathrm{G} \mathrm{Na}$-acetate-1-14 $\mathrm{C}$ and glucose, $2.0 \mathrm{mg}$ per $\mathrm{ml}$ and gassed with $95 \%$ $\mathrm{O}_{2}-5 \% \mathrm{CO}_{2}$. In the experiment in which the preincubation was performed, the same medium described above was used and incubated for $2 \mathrm{hrs}$. under the same conditions and at the end of the preincubation period, the tissues were transferred into a flask which contained fresh medium and incubated for another $2 \mathrm{hrs}$. NADPH and cyclic AMP were dissolved into $0.2 \mathrm{ml}$ KrebsRinger-bicarbonate buffer solution and added to the incubation flask.

At the end of the incubation period, the tissues were separated from the incubation medium, rinsed with ice-cold $0.154 M \mathrm{KGl}$ and homogenized with $4 \mathrm{ml} 0.154 \mathrm{M} \mathrm{KCl}$ solution in an all glass homogenizer. The resultant homogenate was immediately centrifuged in the cold at $600 \mathrm{xg}$ for $10 \mathrm{~min}$. and the sediment was separated (nuclear fraction). The supernatant was again centrifuged at $15,000 \mathrm{xg}$ for $20 \mathrm{~min}$. and the resultant sediment (mitochondrial fraction) was separated from supernatant (supernatant fraction).

Free, ester sterol and corticosterone were extracted from the fractions with $10 \mathrm{ml}$ acetone: ethanol: ether-4-4:1 mixture. Free, ester sterol and corticoterone were separated from each other by thin-layer chromatography as described by Armstrong et al. (1964) and ester sterol was hydrolyzed by the method of Mann (1961). Purification of sterol was carried out by digitonin precipitation followed by another thin-layer chromatography in hexane: ethyl acetate 6:1. The isolation of corticosterone from the incubation media was carried out by extracting with 2 volumes of methylene chloride three times. The purification of corticosterone isolated from both tissues and media was carried out by the method described previously (Ichii et al., 1964).

Corticosterone was determined by its absorption at $240 \mathrm{~m} \mu$ and sterol was determined by the method of Mann (1961). Radioactivity measurements were carried out in a Packard Tri Carb liquid scintillation spectrometer model $314 \mathrm{EX}$.

\section{RESULTS}

In Table 1, the specific activities and amounts of free, ester sterol and corticosterone isolated and purified from the rat adrenal subcellular components and the incubation media are summarized. In this experiment, in order to obtain specific activities of substances, rigorous purification was carried out and the recovery of each sample at the end of purification procedure was not corrected. However, it was found in preliminary experiments using cholesterol-1, $2{ }^{3} \mathrm{H}$ and corticosterone-1, $2{ }^{3} \mathrm{H}$ as internal standards for recovery correction that $86 \%$ of free cholesterol and $67 \%$ of corticosterone radioactivity added were recovered from the adrenal tissue after the same purification procedure employed in this experiments. However, bromination and debromination procedure (Schwenk and Werthessen, 1952) to purify cholesterol from "high counting companion" could not be applied in this experiment because the amount of sterol separated from the tissue was considered to be unsuitable to do so.

The incorporation of radioactivity was observed in all the fractions of incubated adrenal and the marked elevation of specific activity was noted in free sterol and corticosterone of preincubated tissue. The specific activities of free sterol were always higher than those of ester sterol and the free sterol isolated from mitochondrial fraction showed highest specific activity among the free sterol isolated from subcellular fractions of the incubated tissue. This might suggest that the mitochondria are the main site responsible for the sterol biosynthesis from acetate in vitro and that ester sterol may be inert in the corticosteroidogenesis in rat 
Table 1. Incorporation of acetate- $1-{ }^{14} \mathrm{C}$ into free, ester sterol and corticosterone of the subcellular components of rat adrenal gland

\begin{tabular}{|c|c|c|c|c|c|c|}
\hline & \multicolumn{2}{|c|}{ Free sterol } & \multicolumn{2}{|c|}{ Ester sterol } & \multicolumn{2}{|c|}{ Corticosterone } \\
\hline & Amount* & Sp. Act. $* *$ & Amount & Sp. Act. & Amount & Sp. Act. \\
\hline \multicolumn{7}{|l|}{ Control } \\
\hline Nuclear & 1121 & 1.13 & 3272 & 0.76 & \multirow{3}{*}{16.3} & \multirow{3}{*}{7.49} \\
\hline Mitochon. & 1402 & 2.42 & 3085 & 0.97 & & \\
\hline Super. & 267 & 1.02 & 1730 & 0.96 & & \\
\hline Medium & & & & & 51.3 & 1.51 \\
\hline \multicolumn{7}{|c|}{6 umoles NADPH } \\
\hline Nuclear & 1263 & 1.86 & 2489 & 0.92 & \multirow{3}{*}{21.2} & \multirow{3}{*}{4.82} \\
\hline Mitochon. & 1308 & 3.03 & 2992 & 0.79 & & \\
\hline Super. & 90 & 1.18 & 897 & 0.63 & & \\
\hline Medium & & & & & 97.9 & 1.06 \\
\hline \multicolumn{7}{|c|}{ Control_preincubated $\sharp$} \\
\hline Nuclear & 1822 & 3.84 & 2993 & 2.19 & \multirow{3}{*}{10.2} & \multirow{3}{*}{14.99} \\
\hline Mitochon. & 1637 & 8.01 & 2530 & 3.43 & & \\
\hline Super. & 345 & 4.82 & 1366 & 3.12 & & \\
\hline Medium & & & & & 29.4 & 7.13 \\
\hline \multicolumn{7}{|c|}{6 umoles NADPH--preincubated } \\
\hline Nuclear & 1730 & 3.52 & 3338 & 1.58 & \multirow{3}{*}{19.7} & \multirow{3}{*}{10.45} \\
\hline Mitochon. & 1802 & 4.24 & 2712 & 2.02 & & \\
\hline Super. & 234 & 3.17 & 737 & 1.03 & & \\
\hline Medium & & & & & 60.2 & 4.94 \\
\hline
\end{tabular}

Four hundred $\mathrm{mg}$ of quartered rat adrenal obtained from 10 rats were incubated in $4 \mathrm{ml} \mathrm{Krebs}$ Ringer-bicarbonate buffer solution containing $20 \mu \mathrm{C}$ acetate- $1-{ }^{14} \mathrm{C}$ at $37^{\circ} \mathrm{C}$ for $2 \mathrm{hrs}$. in $95 \% \mathrm{O}_{2}$ and $5 \% \mathrm{CO}_{2}$. NADPH was dissolved in $0.2 \mathrm{ml} \mathrm{Krebs}$-Ringer-bicarbonate buffer solution and added to the incubation medium.

* Amount was expressed as $\mu \mathrm{g}$ per g tissue.

** Specific activity was expressed as dpm per $\mu \mathrm{g}$ of substance.

\# The preincubation was carried out in the same medium under the same conditions of the incubation. At the end of preincubation period, tissues were transferred into fresh medium and incubated for another 2 hrs.

adrenal gland.

The specific activity of the corticosterone isolated from the incubation medium after preincubation was about 6.5 times higher than that isolated from the incubation medium in the control; in NADPH supplemented incubations, it was about 5 times as great as in a corresponding control. The increment in free sterol specific activity was only 3 and 1.5 times in both preincubated and non-preincubated tissues, respectively. These results might be explained by suggesting that the corticosterone is mainly derived from non-labelled endogenous precursor cholesterol pool at the beginning of incubation and that the rate of corticosterone formation from cholesterol is much faster than the rate of formation of precursor cholesterol from acetate. The specific activity of corticosterone isolated from incubated tissue was always higher than that isolated from the incubation medium. 
Furthermore, the specific activity of tissue corticosterone was even higher than that of mitochondrial free sterol under all the incubation conditions employed here. However, close correlation was observed between the increment of the specific activities of tissue, medium corticosterone and that of mitochondrial free sterol. From these results, it would appear likely that only a fraction of the mitochondrial free cholesterol was utilized for corticosterone biosynthesis.

The additions of NADPH to incubation media resulted in a lower specific activity in both mitochondrial free sterol and corticosterone. The lower corticosterone specific activity in the incubation medium could be the result of the large amount of corticosterone formed before the radioactive precursor is formed from acetate, since supplementation with $\mathrm{NADPH}$ stmiulated the formation of corticosterone about 2 fold during the preincubation period.

Effects of the treatment of animal with ACTH in vivo or addition of cyclic AMP to the incubation medium on the incorporation of acetate-1 $-{ }^{14} \mathrm{C}$ into free, ester sterol and corticosterone were studied. The results are summarized in Table

Table 2. Effect of ACTH in vivo and cyclic AMP in vitro on the incorporation of acetate-1 $-{ }^{14} \mathrm{C}$ in free, ester sterol and corticosterone of the subcellular components of rat adenal gland

\begin{tabular}{|c|c|c|c|c|c|c|}
\hline & \multicolumn{2}{|c|}{ Free sterol } & \multicolumn{2}{|c|}{ Ester sterol } & \multicolumn{2}{|c|}{ Corticosterone } \\
\hline & Amount* & Sp. Act.** & Amout & Sp. Act. & Amount & Sp. Act. \\
\hline \multicolumn{7}{|l|}{ Control } \\
\hline Nuclear & 1394 & 3.90 & 3892 & 0.82 & & \\
\hline Mitochon. & 2073 & 7.17 & 4027 & 0.94 & 19.0 & 13.83 \\
\hline Super. & 218 & 3.00 & 2390 & 0.75 & & \\
\hline Medium $1^{\circ}$ & & & & & 49.1 & 1.00 \\
\hline Medium $2^{\circ \circ}$ & & & & & 46.0 & 4.58 \\
\hline \multicolumn{7}{|c|}{$A C T H$ treated $\sharp$} \\
\hline Nuclear & 1410 & 10.80 & 3483 & 1.17 & & \\
\hline Mitochon. & 1523 & 19.44 & 3620 & 1.20 & 13.9 & 26.29 \\
\hline Super. & 320 & 7.68 & 1955 & 0.83 & & \\
\hline Medium 1 & & & & & 86.2 & 0.95 \\
\hline Medium 2 & & & & & 45.3 & 4.91 \\
\hline \multicolumn{7}{|c|}{5 umoles cyclic $A M P$} \\
\hline Nuclear & 2317 & 3.64 & 4298 & 0.58 & & \\
\hline Mitochon. & 1754 & 5.76 & 3956 & 0.83 & 17.4 & 18.48 \\
\hline Super. & 415 & 3.05 & 1085 & 1.37 & & \\
\hline Medium 1 & & & & & 77.1 & 0.77 \\
\hline Medium 2 & & & & & 68.2 & 3.16 \\
\hline
\end{tabular}

The incubation conditions were the same as those of Table 1. Cyclic AMP was dissolved in $0.2 \mathrm{ml}$ Krebs-Ringer-bicarbonate buffer solution and added to the incubation medium.

* Amount was expressed as $\mu \mathrm{g}$ per $\mathrm{g}$ tissue.

** Specific activity was expressed as dpm per $\mu \mathrm{g}$ substance.

- Pre-incubation medium

- Incubation medium

\# Animals were received $5 \mathrm{v}$. ACTH intraperitoneally 2 hrs. before sacrifice. 
2. In this experiment, all the tissues were preincubated for $2 \mathrm{hrs}$. in the same medium used for the incubation. The adrenals obtained from the animals which received 5 units of ACTH intraperitoneally $2 \mathrm{hrs}$. before sacrifice produced more corticosterone than did the control during the preincubation period but the amount of corticosterone formed by adrenals from ACTH treated animals during the incubation period was almost the same as that formed by the control adrenals. Although the addition of cyclic AMP stimulated corticosterone biosynthesis throughout the experimental period, the specific activities of corticosterone isolated from the pre- and incubation media were lower than that of the control. This is analogous to the results obtained with the NADPH supplemented incubation. A remarkable incorporation was observed in the free sterol and the tissue corticosterone of ACTH treated adrenal where the specific activites of these substances increased about 2.5 times over the control. In contrast to the ACTH treated adrenal, the specific activity of free sterol isolated from the tissue incubated in the presence of cyclic AMP was lower than those of the control. A large incorporation of radioactive acetate into free sterol of corpus lutea of rats has also been observed by Armstrong et al. (1964) after the animals were treated with luteinizing hormone. A higher specific activity of corticosterone as compared with mitochondrial free sterol was also observed in this experiment.

According to the results of Cornforth et al. (1956), cholesterol biosynthesized from acetate- $1-{ }^{14} \mathrm{C}$ possesses 12 radioactive carbons out of 27 and 10 out of 21 in the case of corticosterone. No correction has been applied in this experiments, since the contribution due to this difference would not make significant differences in the results obtained.

\section{DISGUSSION}

Péron has presented a stoichiometric evidence to establish that corticosterone is biosynthesized from mitochondrial, free cholesterol in rat adrenal gland (Péron, 1964). The pool size of endogenous steroid hormone precursor cholesterol has been assessed approximately by using cholesterol side-chain cleaving enzyme system and it was suggested that the precursor cholesterol is possibly of mitochondrial origin (Ichii et al., 1965). However, it was revealed that the specific activity of corticosterone isolated from adrenal tissue incubated with acetate-1-14 $\mathrm{C}$ was higher than that of mitochondrial free sterol in the same tissue and this was also true when the biosynthesis of corticosterone was stimulated by ACTH in vivo or NADPH and cyclic AMP in vitro. This would suggest that only a fraction of the mitochondrial free sterol was being drawn upon for corticosterone biosynthesis.

A remarkably high specific activity was observed in mitochondrial free sterol after the incubation of adrenals obtained from the animals treated with ACTH. The amount of endogenous steroid hormone precursor cholesterol in rat adrenal gland has been observed to be diminished markedly after ACTH treatment (Ichii et al., 1965). The locus of sterol biosynthesis from acetate in rat adrenal under the conditions employed in this experiments seems to be in the mitochondria. This may explain the high specific activity of mitochondrial free sterol following 
the treatment of animal with ACTH. The similar findings have been reported in rat corpus lutea after the treatment of animal with luteinizing hormone (Armstrong et al., 1964).

Krum et al. (1964) fed cholesterol-4-14 $\mathrm{C}$ to dogs for more than 30 days and compared the specific activity of plasma and adrenal cholesterol and they found that the plasma cortisol had the same specific activity as the adrenal and plasma cholesterol. These result suggest that biosynthesis of cholesterol is not taking place in dog adrenal and consequently, steroid hormone precursor cholesterol in the adrenal is derived completely from exogenous cholesterol. On the other hand, Werbin and Chaikoff (1961) performed a similar experiment using guinea pigs as experimental animals and found only $60 \%$ of the specific activity of plasma cholesterol in adrenal cholesterol which suggested that $40 \%$ of adrenal cholesterol synthesized in the gland contributed to serve the precursor for corticosterone biosynthesis in this animal. In our experiments, significant incorporation of radioactivity from acetate- $1-{ }^{14} \mathrm{C}$ was observed in the sterol of all the subcelluiar components of rat adrenal and in the corticosterone biosynthesized during the incubation period but the physiological significance of sterol synthesized in the tissue is not yet known in the case of rat adrenal gland.

The results obtained in this experiment did not exclude the possibility of the existence of an alternative pathway, which does not involve cholesterol in corticosteroidogenesis in rat adrenal. However, from the fact that close correlation was observed between tissue, medium corticosterone specific activity and that of mitochondrial free sterol in any incubation conditions employed, that possibility seems to be least likely.

\section{SUMMARY}

The analysis of the specific activity of free, ester sterol and corticosterone in the subcellular components of rat adrenal gland after incubation with acetate- $1-{ }^{14} \mathrm{C}$ revealed that the mitochondrial free sterol seems to be the main source of the corticosterone biosynthesized in that tissue. However, the specific activity of corticosterone isolated from the incubated tissue was higher, irrespective of the incubation conditions used, than that of mitochondrial free sterol. This may suggest that a fraction of mitochondrial free sterol appeared to be drawn upon for corticosterone biosynthesis.

\section{REFERENCES}

Armstrong, D.T., J. O'Brien and R.O. Greep (1964). Endocrinology 75, 488.

Bligh, E.G., R.D. Heard, V.J. O'Donnell, J.L. Webb. M. Saffran and E. Schonbaum (1955). Arch. Biochem. Biophys. 58, 249.

Brady, R.O. (1951). J. Biol. Chem. 193, 145.

Cornforth J.W., I. Youhotsky and G. Popjak (1956). Biochem. J. 64, 38.

Hall, P.E. (1963). Biochemistry 2, 1232.

Haynes R., K. Savard and R.I. Dorfman (1954). J. Biol. Chem. 207, 925. 
Hechter, O., M.M. Solomon, A. Zaffaroni and G. Pincus (1953). Arch. Biochem. Biophys. 46, 201.

Ichii, S., S. Kobayashi and M. Matsuba (1965). Steroids 5, 663.

Krum, A.A., M.D. Morris and L.L. Bennett (1964). Endocrinology 74, 543.

Mann, G.V. (1961). Clin. Chem. 7, 275.

Péron, F.G. (1964)- Biochim. Biophys. Acta 82, 125.

Schwenk, E. and N.T. Werthessen (1952). Arch. Biochem. Biophys. 40, 334.

Werbin, H. and I.L. Chaikoff (1961). Arch. Biochem. Biophys. 93, 476.

Zaffaroni A., O. Hechter and G. Pincus (1951). J. Am. Chem. Soc. 73, 1930. 